\title{
Comparison of the expression of p53, p21, Bax and the induction of apoptosis between patients with basal cell carcinoma and normal controls in response to ultraviolet irradiation
}

\author{
M Murphy, M J E M F Mabruk, P Lenane, A Liew, P McCann, A Buckley, C O Flatharta, \\ D Hevey, P Billet, W Robertson, S Javed, M Leader, E Kay, G M Murphy
}

J Clin Pathol 2002;55:829-833

The first two authors contributed equally to this work

\begin{abstract}
Aim: Ultraviolet light (UV) is known to cause DNA damage in the epidermis. The damaged DNA is repaired or deleted by apoptosis to prevent the generation of cancer. It has been suggested that a deficient apoptotic mechanism may predispose individuals to skin cancer. Therefore, the response of normal controls and patients with basal cell carcinoma (BCC) to UV irradiation was investigated. Methods: The buttock skin from normal volunteers and patients with BCC was irradiated using solar simulated radiation (SSR). SSR mimics the effect of natural sunlight. Skin biopsies were excised and examined for p53, p21, and Bax protein expression and for the induction of apoptosis. Results: At 33 hours after UV irradiation, the induction of apoptosis was significantly higher $(p=0.04)$ in patients with BCC than in normal volunteers (Mann Whitney test). A trend towards higher p2 1 expression was found at 33 hours in patients with BCC (mean, 18.69 positive cells/field) than in normal volunteers (mean, 9.89), although this difference was not significant $(p=0.05$ positive cells/field). Conclusion: These results may imply that patients with BCC have enhanced sensitivity to UV irradiation or that there is some defect in the cell arrest or repair pathways, which results in damaged cells been pushed into apoptosis rather than repair.
\end{abstract}

See end of article for authors' affiliations

Correspondence to: Dr M Mabruk, Department of Pathology, Beaumont Hospital, Beaumont Road, Dublin 9, Ireland; mmabruk@rcsi.ie

Accepted for publication 14 April 2002

$\mathrm{U}$ ltraviolet light (UV) is known to cause DNA damage in the epidermis. ${ }^{1-3}$ The damaged DNA is repaired or deleted by apoptosis to prevent the generation of cancer. $^{4-6}$ It has been suggested that a deficient apoptotic mechanism may predispose individuals to skin cancer..$^{6-8}$

\begin{abstract}
"It is not surprising that people most at risk for basal cell carcinoma are individuals with outdoor jobs or those who have been exposed to the sun by frequent holidays in countries with a high sun index"
\end{abstract}

Basal cell carcinomas (BCCs) are the most common skin cancers reported. ${ }^{9-11}$ They are derived from aberrant keratinocytes possibly related to follicular epithelium. White individuals are most frequently affected and are most at risk between 40 and 79 years of age. ${ }^{9}$ The incidence of this cancer correlates with the UV radiation present in natural sunlight. ${ }^{12-14}$ BCCs mostly appear on sun exposed regions (face and arms). ${ }^{9}$

UV is known to induce epidermal DNA damage. ${ }^{2}{ }^{15-18}$ This damage is usually removed by repair pathways, ${ }^{19} 20$ or if the damage is too severe programmed cell death (apoptosis) will ensue. Apoptosis is a physiological process that results in the non-inflammatory elimination of unwanted or damaged cells. ${ }^{21}$

It is thought that with repeated exposure of the skin to UV there is an increased likelihood that a damaged keratinocyte will escape surveillance and will lead to cell progeny with gross chromosomal abnormalities, resulting in the generation of skin cancer. ${ }^{22}{ }^{23}$ Therefore, it is not surprising that people most at risk for BCC are individuals with outdoor jobs or those who have been exposed to the sun by frequent holidays in countries with a high sun index. ${ }^{24}$

It has also been shown that inherent deficiencies, such as less efficient DNA repair pathways, can be responsible for the generation of cancer, as exemplified by Xeroderma pigmentosum. ${ }^{25}{ }^{26}{ }^{27}$ It has also been suggested that individuals with deficient apoptotic pathways might be at risk. ${ }^{68}$

Apoptosis is carried out by a complex set of DNA dependent or DNA independent pathways. ${ }^{4-6}$ The 553 pathway is perhaps the best characterised mechanism of defence, ${ }^{28}$ and its malfunction has been shown to be a major predisposing factor in the development of skin cancer. ${ }^{28-31}$ The wild-type $\mathrm{p} 53$ protein is upregulated in the epidermis after UV exposure. ${ }^{32-34}$ It is a transcription factor that is activated by phosphorylation..$^{28356}$ It either upregulates p21, causing cell cycle arrest, ${ }^{37}{ }^{38}$ followed by repair of damaged DNA, or it upregulates the expression of Bax, which results in the induction of apoptosis. ${ }^{28-39}$

Our study was designed to determine the effect of UV on the expression of p53, p2 $1^{\text {watl/cip } 1}$, and Bax and the induction of apoptosis in vivo in previously non-sun exposed buttock skin in normal controls and patients with BCC to identify a possible inherent susceptibility to BCC.

\section{MATERIALS AND METHODS}

\section{Patient recruitment and UV source}

Ethical approval for our study was obtained from Beaumont Hospital ethics committee. Seventeen control volunteers with benign skin disorders unrelated to sun exposure and 19 patients with BCC attending the dermatology clinics were recruited after informed consent. Volunteers were irradiated

Abbreviations: BCC, basal cell carcinoma; H\&E, haematoxylin and eosin; SSC, solar simulated radiation; TUNEL, terminal deoxynucleotidyl transferase mediated dUTP nick end labelling; UV, ultraviolet light 
Table 1 Details of the irradiation given to patients with basal cell carcinoma (BCC) and normal controls (NC)

\begin{tabular}{llllll}
\hline NC/BCC & Number & Time (hours) & MED & Av. Mi/cm & $p$ Value \\
\hline NC & 3 & 4.5 & 3 & 860 & 0.399 \\
BCC & 2 & 4.5 & 3 & 720 & \\
NC & 4 & 9 & 3 & 720 & 0.147 \\
BCC & 4 & 9 & 3 & 870 & \\
NC & 4 & 24 & 3 & 735 & 0.341 \\
BCC & 4 & 24 & 3 & 900 & \\
NC & 7 & 33 & 3 & 754 & 0.767 \\
BCC & 8 & 33 & 3 & 780 & \\
NC & 4 & 48 & 3 & 915 & 0.3 \\
BCC & 5 & 48 & 3 & 792 & \\
NC & 2 & 72 & 3 & 600 & 0.096 \\
BCC & 3 & 72 & 3 & 840 & \\
\hline
\end{tabular}

Time, refers to the number of hours after UV irradiation at which the biopsy was taken; MED, the number of MEDs administered to the patient; $\mathrm{Av} . \mathrm{mj} / \mathrm{cm}^{2}$, the average of the doses of solar simulated radiation administered to a group of patients.

with three times the predetermined minimal erythema dose using solar simulated radiation (SSR), equivalent to exposure to natural sunlight at midday at $40^{\circ}$ latitude, as described by Murphy et al..$^{40}$ No significant difference between the UV doses received by the patients with BCC and the doses received by the normal controls (table 1) was found using the Student's $t$ test. Four millimetre punch biopsies were taken at 4.5, 9, 24, 33, 48, and 72 hours after SSR. A control biopsy was taken from each volunteer from non-irradiated buttock skin. Some individuals gave more then one irradiated biopsy (in some cases, more than one irradiated biopsy was taken from the same individual; the dose of radiation was the same but the biopsy was excised at a different time point). Therefore, in total, 24 post UV irradiation punch biopsies were taken from controls (three at 4.5 hours, four at 9 hours, four at 24 hours, seven at 33 hours, four at 48 hours, and two at 72 hours) and 26 post UV irradiation punch biopsies were taken from patients with BCC ( two at 4.5 hours, four at 9 hours, four at 24 hours, eight at 33 hours, five at 48 hours, and three at 72 hours). All tissues were fixed in 10\% unbuffered formalin, paraffin wax embedded, and $4 \mu \mathrm{m}$ serial sections were cut. Results from all biopsies were used in the statistical analysis.

\section{p53, p21, and Bax immunohistochemistry}

Serial sections were stained with each antibody, using the avidin-biotin peroxidase complex method, as described previously. ${ }^{40}{ }^{43}$ Positive control slides were included in all tests and consisted of paraffin wax sections from tissues known to be positive for p53, p21, and Bax. In addition, a negative control was included, in which primary antibody was replaced with buffer.

\section{Detection of apoptosis}

The induction of apoptosis was determined using two different approaches.

\section{Haematoxylin and eosin (H\&E) staining}

As described previously, serial sections were stained with H\&E. Features characteristic of apoptosis ${ }^{18}{ }^{40}$ were identified using microscopy by two different observers. It is important to note that sunburn cells were regarded as apoptotic cells in a different phase of apoptosis (prefragmentation) than cells where DNA fragmentation was visible on H\&E. That is, sunburn cells were identified by their eosinophilic cytoplasm, whereas apoptotic cells were identified by their shrunken fragmented nuclei.

The in situ cell death detection kit

Nick end labelling of fragmented DNA, the TUNEL (terminal deoxynucleotidyl transferase mediated dUTP nick end labelling) method, was performed using the in situ cell death detection kit (Boehringer Mannheim, Diagnostics and Biochemicals Ltd, East Sussex, UK) according to the manufacturer's instructions. ${ }^{45}$ Both apoptotic cells and sunburn cells were stained brown by TUNEL.

\section{Counting and analysis}

Apoptotic cells on H\&E were defined as cells with visible nuclear fragmentation or pyknotic nuclei with eosinophilic cytoplasm, and apoptotic cells staining with the in situ cell death kit in addition to immunopositive (p53, p21, and Bax) cells were counted at high magnification $(\times 400)$. Sunburn cells with condensed chromatin, but no fragmented nuclei, were counted separately to determine whether these cells behaved similarly to cells with fragmented DNA. The morphology and percentage of positive cells and the intensity of staining were assessed by two independent observers (MM, MJEMFM). The average number of positive cells in each field was calculated. We used the Mann Whitney test to see whether there were any differences between normal controls and patients with BCC in the response to UV.

\section{RESULTS}

\section{p53 expression}

In normal controls, the expression of p53 was induced immediately after UV exposure at 4.5 hours (mean, 17.67 positive cells/ field; SD, 7.33) (fig lA). Peak expression was seen between 9 (mean, 50.9 positive cells/field; SD, 14.50) and 33 hours after UV irradiation (mean, 65.42 positive cells/field; SD, 13.84). Expression began to level off between 48 hours (mean, 40.99 positive cells/field; SD, 10.16) and 72 hours after UV irradiation (mean, 48.42 positive cells/field; SD, 13.37). The time course in patients with BCC was found to be similar to normal controls. The staining of positive cells in both groups was of similar intensity and positivity was located throughout the epidermis.

Using the Mann-Whitney test no significant differences were found between the two groups. 

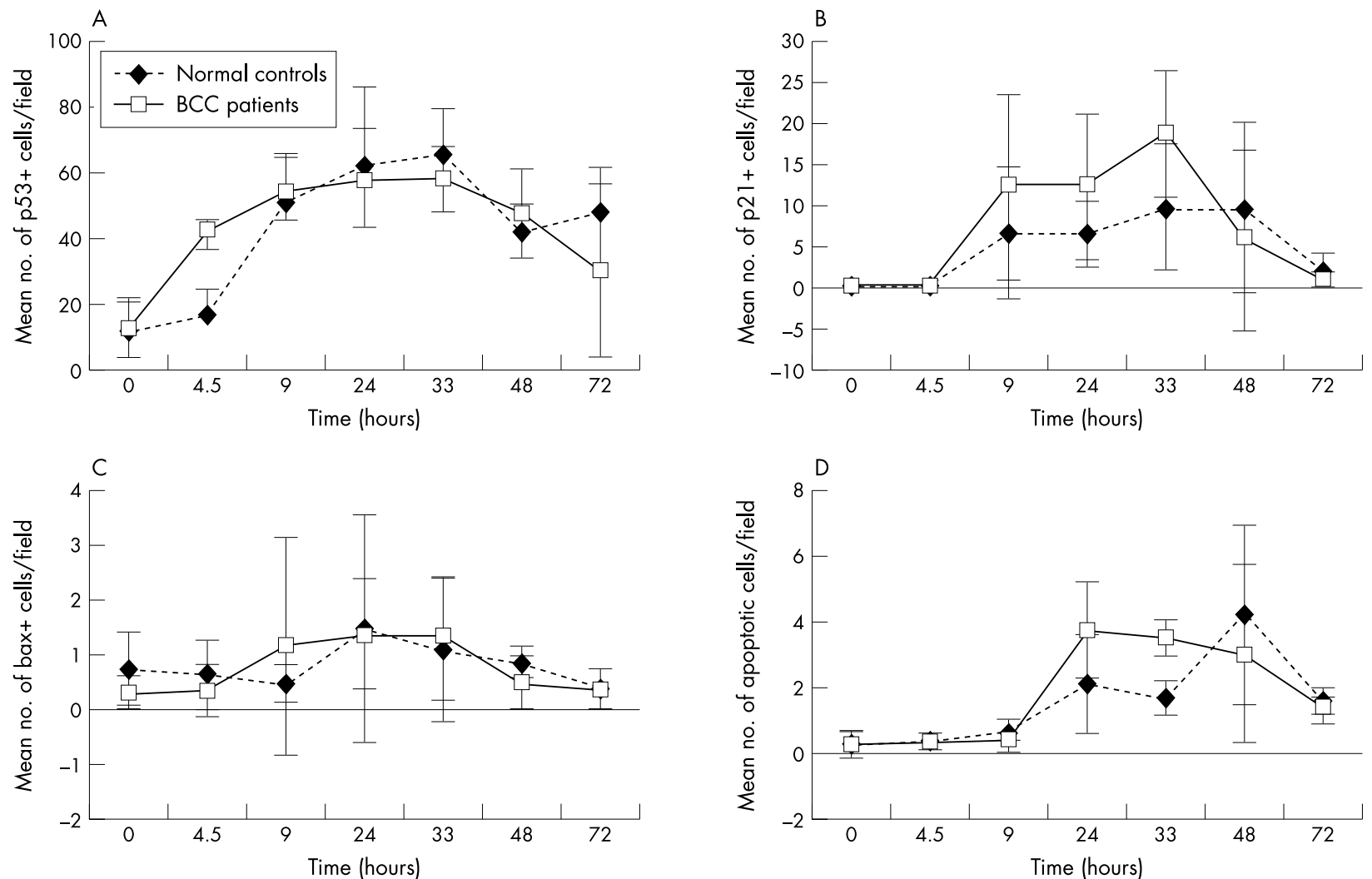

Figure 1 The effect of ultraviolet irradiation in normal controls and patients with basal cell carcinoma (BCC) on (A) the expression of p53, (B) the expression of $\mathrm{p} 21,(\mathrm{C})$ the expression of Bax, and (D) the induction of apoptosis.

\section{p21 expression}

In normal controls, p21 expression was initiated at 9 hours (mean, 6.78 positive cells/field; SD, 7.97) (fig 1B) after UV irradiation. This expression peaked between 33 hours (mean, 9.79 positive cells/field; SD, 7.41) and 48 hours (mean, 9.67 positive cells/field; SD, 10.36) and then declined at 72 hours after UV irradiation (mean, 2.45 positive cells/field; SD, 2.08). In patients with BCC, a trend towards higher p2l expression was seen: 9 hours (mean, 12.27 positive cells/field; SD, 11.13), 24 hours (mean, 12.21 positive cells/field; SD, 8.70), and 33 hours after UV irradiation (mean, 18.69 positive cells/field; SD, 7.73). Although none of these values was significantly different from normal controls, at 33 hours it was close to significance $(p=0.54)$.

\section{Bax expression}

In normal controls, Bax expression was first seen at 4.5 hours (mean, 0.61 positive cells/field; SD, 0.63) (fig 1C) after UV irradiation, reached a peak at 24 hours (mean, 1.45 positive cells/field; SD, 2.06), and declined from 33 hours (mean, 1.09 positive cells/field; SD, 1.32) to 72 hours (mean, 0.39 positive cells/field; SD, 0.01). In patients with BCC, the time course appeared to be similar except that Bax expression peaked slightly earlier at 9 hours (mean, 1.14 positive cells/field; SD, 1.99) and was sustained until 33 hours (mean, 1.31 positive cells/field; SD, 1.14). It then declined from 48 hours (mean, 0.46 positive cells/field; SD, 0.49 ) to 72 hours (mean, 0.36 positive cells/field; SD 0.36 ). Using the Mann-Whitney test no significant difference was found between the two groups.

\section{The induction of apoptosis}

Apoptosis was detected and scored by means of the in situ cell death kit and H\&E staining. The pattern of response was found to be the same for both methods. This indicated that data generated by counting apoptotic cells as assessed by H\&E staining were comparable to data generated by the in situ cell death detection kit (fig 2). Sunburn cells and DNA fragmented

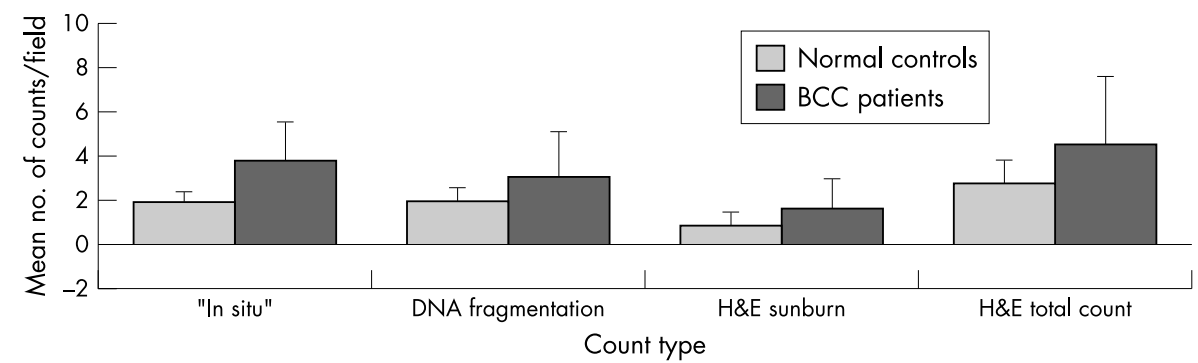

Figure 2 Comparison of apoptosis measured by the in situ cell death detection kit and by haematoxylin and eosin (H\&E) 33 hours after ultraviolet irradiation. Using the H\&E stain, cells showing nuclear fragmentation and sunburn cells (cells with eosinophilic cytoplasm) were both identified. With this stain, the number of cells with fragmented nuclei and sunburn cells were counted both separately and together. It was shown that the two methods were comparable-by taking a time point and plotting the counts obtained by both methods a similar trend was seen in both normal controls and patients with basal cell carcinoma (BCC). 
cells stained with TUNEL, indicating that both represent apoptotic cells.

In normal controls, apoptosis was initiated between 9 hours (mean, 0.66 apoptotic cells/field; SD, 0.32) (fig lD) and 24 hours after UV irradiation (mean, 2.08 apoptotic cells/field; SD, 1.52), peaked at 48 hours (mean, 4.22 apoptotic cells/field; SD, 2.73), and declined at 72 hours (mean, 1.61 apoptotic cells/field; SD, 0.39). This response was altered in patients with BCC in that apoptosis peaked earlier at 24 hours after UV irradiation (mean, 3.69 apoptotic cells/field; SD, 1.61) and remained high up to 48 hours (mean, 3.02 apoptotic cells/field; $\mathrm{SD}, 2.18$ ). The difference between the two groups at the 33 hour time point was found to be significant $(\mathrm{p}=0.04)$ using a Mann-Whitney test.

\section{DISCUSSION}

BCCs are the most common skin cancer in the Western world. ${ }^{9-11}$ Causes of BCC involve UV induced or inheritable p53 or patched gene mutations. ${ }^{41-43}$ p53 mutations result in the loss of cell arrest and hence damaged cells are not repaired or deleted. ${ }^{28-31}$ Patched gene mutations or mutations of other genes involved in the hedgehog pathway result in the upregulation of pathways that cause increased proliferation, such as the ras-ERK pathway. ${ }^{44}$ Hence, disruption of cell cycle arrest and or of hedgehog signalling predisposes to BCC. ${ }^{28-31} 45$

$\mathrm{UV}$ is a major risk factor for BCC and it has been suggested that inefficient apoptosis has a role in the genesis of neoplasia..$^{6-8}$ Apoptosis is a truly error free method of deleting DNA damaged cells, whereas DNA repair mechanisms are error prone. It was shown that resistance to Fas mediated apoptosis develops in a cell model of human proliferative breast disease (a precursor to breast cancer), ${ }^{46}$ and also that tumour angiogenesis, which promotes growth and metastasis of lung cancer, inhibits apoptosis. ${ }^{47}$ These findings have led to the proposal that inefficient apoptosis could be a risk factor that leads to the development of mutations seen commonly in BCCs.

Therefore, in our study, buttock skin (previously nonexposed skin) from patients with BCC and normal controls was irradiated, biopsies were excised, and these were examined for p53, p21, and Bax protein expression and the induction of apoptosis.

\section{"Patients with basal cell carcinoma seem to be inherently predisposed to UV induced cellular damage"}

We found that apoptosis occurred via the $\mathrm{p} 53$ pathway. That is, in normal controls, p53 expression began at 9-33 hours, followed by p21 expression (33-48 hours), and then Bax expression (24 hours), and apoptosis was induced 48 hours after UV irradiation. In patients with BCC, the response to UV was altered in two ways. First, there was a trend towards higher p2 1 expression. Second, apoptosis was induced earlier in patients with BCC and was significantly higher than that seen in controls 33 hours after UV irradiation $(p=0.4)$.

Although the time course for apoptosis varied between patients with BCC and normal controls, the time course for Bax expression did not. This, coupled with the fact that Bax expression was present at very low levels (peak expression, 1.45 cells/field), suggests that other apoptosis inducing proteins are present-for example, PERP, Fas ligand, tumour necrosis factor $\alpha$, and p53 inducible genes. ${ }^{48-50}$ These genes all initiate cell death and have all been shown to be upregulated by $\mathrm{p} 53$. In addition, apoptosis could also occur through a p53 independent pathway. ${ }^{51}$ Therefore, in the future it would be useful to look at the expression of these proteins to determine whether different apoptotic pathways function in patients with BCC compared with controls.

However, although more work is needed to elucidate which apoptotic pathways are occurring in BCC in comparison with

\section{Take home messages}

- In patients with basal cell carcinoma (BCC) the response to ultraviolet light (UV) was altered in two ways: there was a trend towards higher p21 expression at 33 hours and apoptosis was induced earlier

- Thus, patients with BCC may have enhanced sensitivity to UV irradiation

- Alternatively, there may be some defect in the cell arrest or repair pathways in these patients that results in damaged cells been pushed into apoptosis rather than repair

controls, the end result is the same-apoptosis is occurring earlier in BCCs and is significantly higher at 33 hours. This could suggest that more DNA damage is occurring in patients with BCC (that is, they are more sensitive to insult) or that in these patients cell cycle arrest is faulty.

Higher p2 1 expression in patients with BCC indicates that an increase in cell cycle arrest has occurred. This, coupled with the fact that apoptosis occurs earlier in patients with BCC, suggests that these patients have suffered more DNA damage than normal controls after equivalent UV exposure.

Therefore, patients with BCC seem to be inherently predisposed to UV induced cellular damage. This seems plausible because individuals with increased sensitivity to UV have been recorded $^{52}$ and, in addition, it has been shown that increased vulnerability to sun exposure comes with old age, as does the development of BCC. ${ }^{53}$

p2 1 expression is upregulated in patients with BCC after UV exposure. However, this does not always mean that proper cell arrest has occurred ${ }^{39}$ because other factors, such as a mutant retinoblastoma gene $\mathrm{g}^{54}$ or a lack of essential cofactors, could prevent it. ${ }^{55}{ }^{56}$ Inefficient cell arrest or inefficient cell repair (which has been shown to be a risk factor for BCC) ${ }^{27} 5758$ could result in incomplete surveillance-that is, pushing cells into apoptosis earlier and allowing cells with low damage to go through the cell cycle unchecked, ultimately resulting in duplication of damage and possibly the generation of a tumour. An analogous situation has been seen in LEC cells (a cancer sensitive cell line), where in response to UV irradiation there was an increased sensitivity to apoptosis without cell cycle arrest. ${ }^{59}$ Further support for this argument comes from the fact that BCC tumours have high levels of apoptosis, ${ }^{60}$ indicating that the apoptotic machinery is intact in patients with BCC and that the initial fault must lie elsewhere.

In conclusion, it was found that the response to UV irradiation is altered in patients with BCC when compared with normal controls. This suggests that individuals with BCC have an altered defence mechanism, and further investigations at the molecular level should be carried out to identify this predetermining BCC factor.

\section{ACKNOWLEDGEMENTS}

We would like to acknowledge EU grant number ENV4-CT97-05556 for financial support.

\section{Authors' affiliations}

M Murphy, M J E M F Mabruk, A Liew, C O Flatharta, P Billet, W Robertson, S Javed, M Leader, E Kay, G M Murphy, Department of Pathology, Royal College of Surgeons in Ireland, Dublin 2 and Beaumont Hospital, Dublin 9, Ireland

P Lenane, P McCann, A Buckley, Department of Dermatology, Royal College of Surgeons in Ireland

D Hevey, Department of Psychology, Royal College of Surgeons in Ireland

\section{REFERENCES}

1 Matsunaga T, Hieda K, Nikaido $O$. Wavelength dependent formation of thymine dimers and (6-4) photoproducts DNA by monochromatic ultraviolet light ranging from $150-365 \mathrm{~nm}$. Photochem Photobiol 1991;54:403-10. 
2 Yarosh DB. The role of DNA damage and UV induced cytokines in skin cancer. J Photochem Photobiol B 1992;16:91-4.

3 Young AR, Chadwick CA, Harrison Gl, et al. The similarity of action spectra for thymine dimers in human epidermis and erythema suggests that DNA is the chromophore for erythema. J Invest Dermatol 1998;111:982-8.

4 Orren DK, Petersen LN, Bohr VA. A UV responsive G2 checkpoint in rodent cells. Mol Cell Biol 1995;15:3722-30.

5 Mukhtar H, Forbes MH, Ananthaswamy HN. Photocarcinogenesis models and mechanisms. Photodermatol Photoimmunol Photomed 1999;15:91-5

6 Lenane P, Murphy GM, Kay E, et al. Hypothesis: does sunlight cause cell suicide? Current Diagnostic Pathology 1998;5:204-7.

7 Hermeking $\mathbf{H}$, Eick D. Mediation of c-Myc-induced apoptosis by p53. Science 1994;265:2091-2.

8 Enoch T, Norbury C. Cellular responses to DNA damage: cell cycle checkpoints, apoptosis and the roles of p53 and ATM. Trends Biochem Sci 1995;20:426-30.

9 Miller SJ. Biology of basal cell carcinoma (part 1). J Am Acad Dermato 1991;24:1-13.

10 Scotto J, Fears TR, Fraumeni JF. Incidence of non-melanoma skin cancer in the United States. Washington DC: NIH Publication 83-2433, 1983.

11 Kricker A, English DR, Randle PL, et al. Skin cancer in Geraldton, West Australia: survey of incidence and prevalence. Med J Aust 1990:152:399-407

12 Rady P, Scinicariello F, Wagner RF, et al. p53 mutations in basal cell carcinomas. Cancer Res 1992;52: 3804-6.

13 Ziegler A, Leffell DJ, Kunala S, et al. Mutation hotspots due to sunlight in the p53 gene of nonmelanoma skin cancers. Proc Natl Acad Sci U S A 1993:90:4216-20.

14 Kanfilal S, Strom SS, Clayman GL, et al. p53 mutations in nonmelanoma skin cancer of the head and neck: molecular evidence for field cancerization. Cancer Res 1995;55:3604-9.

15 Epstein EL, Fukuyama, D, Epstein JH. Early effects of ultraviolet light on DNA synthesis in human skin in vivo. Arch Dermatol 1969:100:84-9.

16 Johnson BE. Formation of thymine containing dimers in skin exposed to ultraviolet radiation. Bull Cancer 1978;65:283-97.

17 Harm H. Damage and repair in mammalian cells after exposure to non-ionizing radiations. III. Ultraviolet and visible light irradiation of cells of placental mammals, including humans, and determination of photorepairable damage in vitro. Mutat Res 1980;69:167-76.

18 Young AR. The sunburn cell. Photodermatology 1987;4:127-34

19 Hanawalt PC. Role of transcription-coupled DNA repair in susceptibility to environmental carcinogenesis. Environ Health Perspect 1996;104:547-51

20 Wood RD. DNA repair in eukaryotes. Annu Rev Biochem 1996;64:135-67.

21 Wyllie AH. Apoptosis: an overview. Br Med Bull 1997;73:189-97.

22 Hattori Y, Nishigori C, Tanaka T, et al. 8-hydroxy-2'-deoxyguanosine is increased in epidermal cells of hairless mice after chronic ultraviolet $B$ exposure. J Invest Dermatol 1996; 107:733-7.

23 Soehnge H, Ouhtit A, Ananthaswamy ON. Mechanisms of induction of skin cancer by UV radiation. Front Biosci 1997;2:D538-51.

24 Naldi L, Dilandro A, D'Avanzo B, et al. Host-related and environmental risk factors for cutaneous basal cell carcinoma: evidence from an Italian case-control study. J Am Acad Dermatol 2000;42:446-52.

25 Rosso S, Joris F, Zanetti R. Risk of basal and squamous cell carcinomas of the skin in Sion, Switzerland: a case-control study. Tumori 1999:85:435-42.

26 Kraemer KH, Lee MM, Scotto J. DNA repair protects against cutaneous and internal neoplasia: evidence from xeroderma pigmentosum. Carcinogenesis 1984;5:511-14

27 Wei Q, Matanoski GM, Farmer ER, et al. DNA repair capacity for ultraviolet light-induced damage is reduced in peripheral lymphocytes from patients with basal cell carcinoma. J Invest Dermato 1995;104:933-6.

28 Amundson SA, Myers TG, Fornace AJ. Roles for p53 in growth arrest and apoptosis: putting on the brakes after genotoxic stress. Oncogene 1998; 17:3287-99.

29 Li G, Ho VE, Mitchell DL, et al. Differentiation-dependent p53 regulation of nucleotide excision repair in keratinocytes. Am J Patho 1997; 150: 1457-64

30 Li G, Tron V, Ho V. Induction of squamous cell carcinoma in p53-deficient mice after ultraviolet irradiation. J Invest Dermatol $1998 ; 110: 72-5$

31 Jiang E, Ananthaswamy HN, Muller HK, et al. p53 protects against skin cancer induction by UV-B radiation. Oncogene 1999;1 18:4247-53.

32 Ponten F, Berne B, Ren Z-P, et al. Ultraviolet light induces expression of p53 and p2 1 in human skin. Effect of sunscreen and constitutive p21 expression in skin appendages. J Investig Dermatol 1995;105:402-6.
33 O'Grady A, Kay EW, McKenna DB, et al. Altered expression of the p53-regulated proteins, p2 1 Waf/Cip 1, MDM2, and Bax in ultraviolet-irradiated human skin. Hum Pathol 1998;29:559-64.

34 Davenport V, Morris JF, Motazed R, et al. p53 induction in normal human skin in vitro following exposure to solar simulated UV and UVB irradiation. J Photochem Photobiol B 1999;49:177-86.

35 Lane D. Awakening angels. Nature 1998;394:616-17.

36 Woo RA, Mclure KG, Lees-miller SP, et al. DNA-dependent protein kinase acts upstream of p53 in response to DNA damage. Nature 1998;394:700-4

37 Crook T, Marston NJ, Sara EA, et al. Transcriptional activation by p53 correlates with suppression of growth and not transformation. Cell 1994;79:817-827.

38 Wu L, Levine AJ. Differential regulation of the $\mathrm{p} 21 /$ waf- 1 and mdm2 genes after high doses UV irradiation. p53 dependent and p53 independent regulation of mdm2 gene. Mol Med 1997;3:441-51.

39 Reinke V, Lozano G. Differential activation of p53 targets in cells treated with ultraviolet radiation that undergo both apoptosis and growth arrest. Radiat Res 1997;148:112-15.

40 Murphy $\mathbf{M}$, Mabruk MEMF, Lenane $\mathrm{P}$, et al. The expression of p53, p21, Bax and induction of apoptosis in normal volunteers in response to different doses of ultraviolet radiation. $\mathrm{Br} J$ Dermatol [ln press.]

41 Ling G, Ahmadian A, Persson A, et al. PATCHED and p53 gene alterations in sporadic and hereditary basal cell cancer. Oncogene 2001;20:7770-8

42 Wicking $\mathrm{C}$, McGlinn E. The role of hedgehog signalling in tumorigenesis. Cancer Lett 2001:173:1-7.

43 de GruijI FR, van Kranen HJ, Mullenders LH. UV-induced DNA damage, repair, mutations and oncogenic pathways in skin cancer. J Photochem Photobiol B 2001;63:19-27

44 Xie J, Aszterbaum M, Zhang X, et al. A role of PDGFRalpha in basal cell carcinoma proliferation. Proc Natl Acad Sci U S A 2001;98:9255-9.

45 Bale AE, Yu K-P. The hedgehog pathway and basal cell carcinomas. Hum Mol Genet 2001;10:757-70.

46 Starcevic SL, Elferink C, Novak RF. Progressive resistance to apoptosis in a cell lineage model of human proliferative breast disease. J Natl Cancer Inst 2001;93:776-82.

47 Shi e, Jiang $X$, Li $Y$, et al. Measurement of tumor angiogenesis in primary lung cancer. Zhonghua Wai Ke Za Zhi 2000;38:841-3.

48 Attrardi LD, Reczek EE, Cosmas C, et al. PERP, an apoptosis-associated target of p53, is a novel member of the PMP-22/gas3 family. Genes Dev 2000;14:704-18.

49 Zhuang L, Wang B, Sauder DN. Molecular mechanism of ultraviolet-induced keratinocyte apoptosis. J Interferon Cytokine Res 2000;20:445-54

50 Sheikh MS, Burns TF, Huang Y, et al. P53-dependent and independent regulation of the death receptor KILLER/DR5 gene expression in response to genotoxic stress and tumor necrosis factor alpha. Cancer Res 1998:58:1593-8

51 Aragane Y, Kulms D, Metze D, et al. Ultraviolet light induces apoptosis via direct activation of CD95 (Fas/APO-1) independently of its ligand CD95L. J Cell Biol 1998;140:171-82.

52 Ohta M, Nitta M, Yamaizumi M. High sensitivity of the ultraviolet induced p53 response in ultraviolet sensitive syndrome - a photosensitive disorder with a putative defect in deoxyribonucleic acid repair of actively transcribed genes. Mutat Res 1999;26:23-32

53 Le Varlet B, Chaudagne C, Saunois A, et al. Age-related functional and structural changes in human dermo-epidermal junction components. $J$ Investig Dermatol Symp Proc 1998;3:172-9.

54 Grana X, Garriga J, Mayol X. Role of the retinoblastoma protein family, pRB, p107 and p130 in the negative control of cell growth. Oncogene 1997; 17:3365-83

55 Schreiber M, Muller WJ, Singh G, et al. Comparison of the effectiveness of adenovirus vectors expressing cyclin kinase inhibitors p16 $6^{\mathrm{INK} 4 \mathrm{~A}}$ p1 $8^{\text {INK } 4 C}, \mathrm{p} 19^{\text {INK } 4 D}, \mathrm{p} 21^{\mathrm{WAF1} / \mathrm{CIP1} 1}$ and $\mathrm{p} 27^{\mathrm{KIP} 1}$ in inducing cell cycle' arrest, apoptosis and inhibition of tumorigenicity. Oncogene 1998;18:166376.

56 Yamamoto $\mathbf{H}$, Soh J-W, Shirin $\mathrm{H}$, et al. Comparative effects of overexpression of $\mathrm{p} 27^{\mathrm{Kipl}}$ and $\mathrm{p} 21^{\mathrm{Cipl} / \text { Wafl }}$ on growth and differentiation in human colon carcinoma cells. Oncogene 1999;18:103-15.

57 Alcalay J, Freeman SE, Goldberg LH, et al. Excision repair of pyrimidine dimers induced by simulated solar radiation in the skin of patients with basal cell carcinoma. J Invest Dermatol 1990;95:506-9.

58 Lin AN, Carter DM, Balin AK. Nonmelanoma skin cancers in the elderly. Clin Geriatr Med 1989:5:161-70

59 Hayashi M, Uehara K, Ichikawa Y, et al. Higher sensitivity in induction of apoptosis in fibroblast cell lines derived from LEC strain rats to UV irradiation. J Vet Med Sci 1998;60:207-12

60 Mooney EE, Ruis Peris JM, O'Neill A, et al. Apoptotic and mitotic indices in malignant melanoma and basal cell carcinoma. J Clin Patho 1995:48:242-4. 